\title{
The role of resources and technology in mathematics education
}

\author{
Maria G. Bartolini Bussi • Marcelo C. Borba
}

Accepted: 31 December 2009/Published online: 19 January 2010

(C) FIZ Karlsruhe 2010

Technology has long been a theme open for debate within the mathematics education community and has been reflected in the work of the International Commission on Mathematical Instruction (ICMI) even prior to the first International Congress on Mathematical Education (Lyon, 1969). More recently, information and communication technology (ICT) has played an increasing role in the events organized by ICMI. Debates around ICT have brought to light the fact that other resources and technologies have been introduced over the last 100 years. On the occasion of the 100th anniversary of ICMI, a Symposium was held in Rome to celebrate the event (see Menghini, Furinghetti, Giacardi \& Arzarello, 2008). ${ }^{1}$ In that Symposium, a Working Group was devoted to the issue of resources and technology throughout the history of ICMI (e.g., paper and pencil, memorization and calculators, Dienes blocks, mathematical machines, computers, software and digital learning objects, etc.). More than 20 researchers from all over the world took part in this Working Group, bringing with them their personal experience and informed reviews of the ICMI-related literature in this field. It was clear that a deeper understanding of ICT may be reached only if viewed from an historical

M. G. Bartolini Bussi ( $\square$ )

Dipartimento di Matematica,

Università di Modena e Reggio Emilia,

via Campi 213/B, 41100 Modena, Italy

e-mail: bartolini@unimore.it

\section{C. Borba}

Department of Mathematics, GPIMEM, Graduate Program in Mathematics Education,

Sao Paulo State University "Júlio de Mesquita Filho",

Avenida 24A, 1515 Bela Vista, Rio Claro, SP, Brazil

e-mail: mborba@rc.unesp.br perspective. Euclid's Elements may be considered a modeling theory of geometrical drawing by means of ruler and compasses. The ancient abacus (in region of Rome as well as in the Far East) and the other devices used in preColumbian America can be seen as the roots of the modern positional system of number representation. More recently, the development of perspective drawing in Europe by means of instruments used in painters' studios has laid the foundations for modern development of projective geometry. The present technologies (ICT) are, in some respects, the heirs of this long tradition of mathematical instruments.

In the early years of the twentieth century, when ICMI was constituted, a growing pressure toward the introduction of experimental approaches in the teaching of mathematics appeared. Brock and Price (1980) studied the introduction of squared paper into the mathematics classroom as a symptom of this attitude and related it to three underlying factors: the break-up of the tradition of considering mathematics as merely instrumental in primary school and as an 'art' in secondary education, to discipline the mind, rather than a science; the rise and development of science teaching in schools, and the associated problem of correlating mathematics and science teaching; the development of engineering in its various forms (Brock \& Price, 1980).

John Perry (1913) was one of the champions of the introduction of applied mathematics into mathematics education (a trend later continued by the International Community of Teachers of Mathematical Modelling and Applications, ICTMA, an affiliated study group of ICMI). Perry (1913) introduced "practical mathematics" as a new method of teaching, different from the academic method

\footnotetext{
1 The proceedings of the Symposium are available at http://www. unige.ch/math/EnsMath/Rome2008/.
} 
that was successful "with about $5 \%$ of all students". In this method, great importance is given to resources (taken from the technology of the time), such as the slide rule and squared paper. In the same years, the first president of ICMI, Felix Klein, supported the recourse to the use of ancient instruments in teaching: in his famous books on Elementary mathematics from an advanced standpoint, this use was put in the perspective of the advances of mathematics of the eighteenth and nineteenth centuries.

The attention to resources and technologies emphasized the importance of introducing into school mathematics and into teacher education the complex relationships between mathematics as a "pure" discipline and mathematics as an activity rooted and used in the world of practical experience. This complexity is well represented by the ambiguity in the use of an expression like "mathematical models". This expression may refer to physical representation of mathematical concepts, e.g., reproductions of plane and solid geometric figures made of cardboard, wood, plastic, or other substances; models of conic sections, curves in space, or three-dimensional surfaces of various kinds made of wire, plaster, or thread strung from frames; and models of surfaces of higher order that make it possible to visualize abstract mathematical concepts. Examples may be found in Klein's books on Elementary mathematics from an advanced standpoint, and later in other books (e.g., Cundy $\&$ Rollet, 1961). Yet, in the context of applied mathematics, mathematical models refer rather to mathematical objects which represent the essential aspects of a complex system (Blum, Galbraith, Henn \& Niss, 2007).

In both cases, however, relationships between mathematics and extra-mathematical objects are called into play. In both cases, students are supposed to actively explore some extra-mathematical objects (e.g., a physical model of a mathematical concept, a natural or social phenomenon). At the beginning of the twentieth century, this educational trend in mathematics was well in tune with the development of active methods in education, supported in the same period by John Dewey $(1916,1938)$.

Later, the active participation of students was increasingly supported within a laboratory setting, with hands-on activities and with the introduction of ICT. This experimental approach, where exploration plays a major role, seems appealing for students who quite often find the evidence offered by a particular experiment much more convincing than a rigorous proof and are bored by the request to also produce mathematical arguments. Hence, somebody might suspect that the appeal of the experimental approach obstructs the development of mathematical styles of reasoning. On the contrary, looking at the function of resources and technologies from an historical perspective offers many reasons to support the experimental approach. Moreover, there are now academic publications devoted to experimental aspects of mathematics research that publish formal results inspired by experimentation, conjectures suggested by experiments, descriptions of algorithms, and software for mathematical exploration.

In this special issue, we have collected several research papers that emphasize, on the one hand, the historical roots of the experimental approach drawing on resources and technologies, and on the other hand, show its effectiveness in mathematics education. In other words, we present an international review of the theme Resources and technology throughout the history of ICMI as an historical base, on the one hand, and as a prompt toward future development, on the other hand. The authors come from all continents and have expertise in the didactical use of both classical and ICTs.

Schubring's historical introduction emphasizes different historical aspects of the history of mathematics education, with a major focus on the figure of the first ICMI President, i.e., Felix Klein. Gerdes' contribution focuses on teacher education in Africa, introducing examples related to cultural practices which, in spite of the century-long or even millennial tradition, belong to the recent history of mathematics education. Bartolini's, Taimina's, and Isoda's contributions widen the geographical perspective: the activity in three continents (Europe, America and Asia) is focused in order to study the influence of Klein as well as other contemporary mathematicians on the development of mathematical instruction in Italy, US, and Japan. Three different research centers are described: the Laboratory of Mathematical Machines at the University of Modena and Reggio Emilia (Italy), the pedagogical space of Kinematical Model for Design Digital Library at Cornell (USA), and the Center for Research on International Cooperation in Educational Development at Tsukuba University (Japan). The three centers have maintained the reference to concrete materials (either models or instruments), with original interpretations that take advantage of the different cultural conditions. Although in all cases the reference to history is deep and systematic, the synergy with mathematical modeling and with ICTs has been exploited, not to substitute but to complement the advantages of the direct manipulations.

Villarreal and Borba consider both ancient and modern technologies, introducing the notion of humans-withmedia, in order to discuss the ways that different media have conditioned and dramatically reorganized education in general and mathematics education in particular. They illustrate how medium is related to the scientific production of mathematical knowledge and show how traditional media were introduced into schools and have influenced education. They use the notion of humans-with-media to propose that different artifacts throughout history had an 
active role in knowledge production. In particular, they examine how devices such as blackboards and notebooks, which were novelties a 100 years ago, came to be accepted in schools, and what mathematical activities were promoted with their use. Finally, they discuss how information technology has changed education, and how the Internet may have an impact on mathematics education comparable to that of the notebook over a century ago. The shift and link between resources and ICTs are also the focus of Maschietto's and Trouche's paper. A look at history highlights that the contribution of artifacts to mathematics learning should be considered in terms of various contexts. The contexts are analyzed employing two main theoretical frameworks, the instrumental approach and the semiotic mediation approach from the perspective of mathematics laboratory, to address questions such as: are there "good" contexts in which to develop mathematical instruments? Are there "good" teaching practices which assist students" instrumental geneses and construct mathematical meanings? How is it possible to promote such teaching practices?

Laborde and Straesser take a closer look at the place of computer technology in the last ICMEs and in the two ICMI study. They show how during the last decades and on the two ICMI studies devoted to technology, it is obvious that the role and use of technology has given rise to a diversity of points of view and attitudes across the world. They analyze how different frameworks use different terminology to say similar things and how true differences have emerged in the way technology is used. Robutti's paper shows how two of these different frameworks can be combined to analyze the role of graphing calculators in communication in the classroom. She discusses how graphing calculators (old technology?) can gain a status of new technology if they are connected in a way that students can have their private investigation and share it electronically with colleagues. She uses the notion of multimodality and humans-with-media among others to understand the way students practice mathematics in the classroom.

Lavicza's paper points out that most studies that address the use of ICT focus on secondary education. She presents a discussion about how mathematicians use ICT in their professional research work and how they are used in classroom. The reader will get a glimpse of how mathematicians see the use of technology in classroom.

Healy and Kynigos' illustrate how the use of computer technology has a "history" already. They show how the notion of microworlds and the search for a learnable mathematics have a continued relevance to mathematics education, but that the lens of research attention has shifted over time, with the current foci on communal design, situated and embodied approaches, and artefacts whose use crosses boundaries between different practices. These authors show how one of the oldest expressions in the ICT world has changed overtime. Gadanidis and Geiger's paper, in contrast, looks into the future. They do start analyzing the use of technology in meetings organized by ICMI, but they emphasize how social theories are shifting the focus of research and how theories coming from the performing arts can open up new alternatives for learning mathematics in the twenty-first century. Students performing mathematics in the digital world is one alternative they present.

This special issue analyzes the way artefacts and ICT have been discussed throughout the history of ICMI. On the other hand, it can be seen as a result of its history, since it presents a more mature reflection of part of the discussion of the Working Group of the very special meeting that celebrated the 100 years of ICMI in March of 2008. In a book chapter published after the conference, Borba and Bartolini Bussi (2008) summarized the theoretical issues of the Working Group in the form of questions. Many of them were raised to address the nature of the discussion that took place during the meeting. Some of them were:

Does mathematics remain untouched as different technologies are used? How has software that emphasizes multiple representations of concepts like functions, or dynamic geometry software, changed the status of visualization in mathematics education? ...

Are there differences between the use of the graphing calculator and use of function software in the classroom? What kinds of changes does the Internet bring to mathematics education? Do new technologies transform old ones or erase them? What is the relation between human thinking and the tools that have been developed throughout history? How is the very notion of human body affected by artifacts in general and by computer technology in particular? Are representations of a given mathematical concept being transformed by the different technologies we have experienced in these 100 years of ICMI? Is knowledge produced by a human, by humans, or by collectives of humans-with-media? Has the notion of a problem in the mathematical classroom been affected by different technologies? How has the classroom been affected by the Internet? Are teachers in a new "risk zone" as they cope with new uncertainties resulting from the availability of information and communication technology? (297-298).

In this special issue, the reader will find empirical research approached in a very theoretical way and reviews of research focusing on the use of artefacts in mathematics education. Answers to the open questions raised in 2008 cannot be answered yet, but the reader can find better clues 
to them within this set of papers. We believe this issue is important because it situates the discussion about ICT, and the Internet in particular, within an historical perspective. Tools have been present in mathematics education for a long time (Kidwell et al., 2008). It is important that we try to see the changes that software, digitalized tools of the past, and the Internet in general may bring to mathematics education today without losing perspective on how other artefacts have or have not changed mathematics education in the past.

\section{References}

Blum, W., Galbraith, P. L., Henn, H. W., \& Niss, M. (2007). Modelling and application in mathematics education. The 14th ICMI study. New York: Springer.

Borba, M. C., \& Bartolini Bussi, M. G. (2008). Resources and technology throughout the history of ICMI. In M. Menghini, F. Furinghetti, L. Giacardi, \& F. Arzarello (Eds.), The first century of the International Commission on Mathematical Instruction (1908-2008). Reflecting and shaping the world of mathematics education. Rome: Istituto della Enciclopedia Italiana fondata da Giovanni Treccani.

Brock, W. H., \& Price, M. H. (1980). Squared paper in the nineteenth century: instrument of science and engineering, and symbol of reform in mathematics education. Educational Studies in Mathematics, 11, 365-381.

Cundy, H. M., \& Rollet, A. P. (1961). Mathematical models. New York: Oxford University Press.

Dewey, J. (1916). Democracy and education: An introduction to the philosophy of education. New York: Macmillan.

Dewey, J. (1938). Experience and education. New York: Macmillan.

Kidwell, P. A., Ackerberg-Hastings, A., \& Roberts, D. L. (2008). Tools of American mathematics teaching, 1800-2000. Baltimore: Johns Hopkins University Press.

Menghini, M., Furinghetti, F., Giacardi, L., \& Arzarello, F. (Eds.). (2008). The first century of the International Commission on Mathematical Instruction (1908-2008). Reflecting and Shaping the World of Mathematics Education. Rome: Istituto della Enciclopedia Italiana fondata da Giovanni Treccani.

Perry, J. (1913). Elementary practical mathematics. London: MacMillan. 